\title{
LA METÁFORA TEATRAL EN LA INTERACCIÓN SOCIAL
}

\section{THE THEATRICAL METAPHOR IN SOCIAL INTERACTION}

\author{
Miguel Beltrán Villalva \\ Universidad Autónoma de Madrid. España \\ miguel.beltran@uam.es
}

\section{Resumen}

En la descripción científica de ciertos fenómenos es usual utilizar metáforas que faciliten su investigación y comprensión. La teoría sociológica utiliza la de rol o "papel social" para identificar las expectativas compartidas de conducta en la interacción social. Esta metáfora teatral, o "dramatúrgica", permite construir una noción de homo sociologicus con la que percibir regularidades sociales que pueden ser calificadas de rituales, dotando asi a la idea de drama ritual de una potente capacidad heurística. Capacidad que debe tener en cuenta el riesgo epistemológico de suponer que nuestro conocimiento de la realidad social la refleja literal y fielmente, olvidando la ambigüedad y la contingencia que la caracterizan.

\section{Palabras Clave}

Homo sociologicus, Realidad social, Regularidades, Ritual, Rol.

\section{Abstract}

The scientific description of some phenomena makes normal use of metaphors in order to facilitate its research and understanding. Sociological theory uses rol to identify the shared expectations of behavior in social interaction. This theatrical, or dramaturgical, metaphor allows the construction of the notion of homo sociologicus through which it is possible to perceive social regularities that may be labeled as rituals, adding a great heuristic capacity to the idea of ritual drama. But it is necessary to keep in mind the epistemological risk of supposing that our knowledge of social reality is a mirror of nature, forgetting its ambigüities and contingency.

\section{KEYWORDS}

Homo sociologicus, Regularities, Ritual, Rol, Social Reality. 


\section{INTRODUCCIÓN ${ }^{1}$}

Pretendo ocuparme en estas páginas de cuestiones de teoría sociológica, por lo que no estará de más rechazar desde el principio un modo de hacerla que se refiera sólo a textos de sociólogos, ya que en mi opinión el horizonte básico del trabajo teórico ha de ser la realidad social, y teniéndola presente es como debe examinarse el tratamiento que reciba en los textos considerados. Pues bien, traigo aquí a varios autores que comparten la metáfora teatral en su esfuerzo por entender la sociedad, bien atendiendo a los roles o papeles que representamos, bien subrayando el componente ritual que dota a sus pautas de sentido. Pero no voy a hacer un comentario de sus textos como si il n'y a pas de hors-texte, que diría Derrida (1967: 227), sino precisamente desde fuera de ellos, desde la realidad social como yo la concibo, viendo cómo se adecúan a ella. La sociología no debe alimentarse de sociología, sino de la realidad por la que se interesa: en una ciencia con un objeto tan problemático y complejo es obligado cuidar constantemente de no incurrir en alegrías epistemológicas, lo cual implica la necesidad de escribir sobre la teoría sin perder de vista su objeto, la realidad social. Eso es lo que trato de hacer en las páginas que siguen: reflexiones teóricas hechas mirando a la realidad más que a los textos de quienes la han estudiado.

Y tanto más cuanto que los textos que voy a considerar no son descriptivistas, esto es, no tratan de ofrecer una representación más o menos "fotográfica" de la realidad social, sino que son metafóricos: tratan de entender la realidad a través de la metáfora teatral, en el sentido de que en nuestra interacción con los demás representamos papeles que hemos aprendido, y lo hacemos mejor o peor. Si hemos de creer a Ortega, "la metáfora es un instrumento mental imprescindible, es una forma de pensamiento científico [...], un procedimiento intelectual por cuyo medio conseguimos aprehender lo que se halla más lejos de nuestra potencia conceptual" ${ }^{2}$. En todo caso, el lenguaje metafórico nos dice algo acerca de la realidad, aunque hay que evitar su interpretación literal, pues siempre adolece de mayor o menor ambigüedad. Hay, pues, que andarse con cuidado, pues una cosa es la vida social y otra el teatro, aunque es verdad que si, por ejemplo, ejerzo la profesión de médico, me tocará tanto intentar curar las enfermedades de mis pacientes como acomodar mi conducta profesional y social a las expectativas de todos los que tengan que ver con ella (el resto de los médicos, las enfermeras, la gente en general y, por supuesto, mis pacientes). Como dice Erving Goffman, cada uno de nosotros "transforma su trabajo en actuación [...]: no sólo vivimos sino actuamos; componemos y representamos el personaje que hemos elegido" (2006: 67). Si decimos que

\footnotetext{
${ }^{1}$ Estas páginas se han beneficiado de los comentarios de varios colegas y amigos, particularmente de los excelentes y muy minuciosos de Enrique Martín Criado.

2 Véase el espléndido texto (Ortega y Gasset, 1957: 387 y 391). Véanse también Ortony (1979), y Lakoff y Johnson (1991).
} 
la sociedad diseña una serie de "papeles" del tipo de los que escribe un autor teatral para sus personajes, que los aprendemos y los representamos en la interacción social, y que recibimos premios o castigos según los espectadores valoren nuestra representación, estamos quizás entendiendo los complicados procesos del funcionamiento del orden social, pero corriendo el riesgo de ser superficiales y quedarnos en el territorio literario de la metáfora. Pero no estará de más que sea el propio Goffman quien nos ponga en guardia frente a las dificultades de distinguirlas de la realidad: "la vida en sí -nos dice- es algo que se representa en forma dramática. El mundo no es, ciertamente, un escenario, pero no es fácil especificar los aspectos fundamentales que establecen la diferencia" (2006: 83). Pues bien, la diferencia radica en que para los actores que se mueven en la realidad sus acciones no son vividas como teatro, como algo superpuesto a la vida propia, sino como su vida personal, la única que tienen. Cuando decimos que actúan representando un papel aprendido, y que los demás (que son a la vez su público y sus interactores) comparten expectativas acerca de su conducta y aprecian la calidad de la performance ofrecida premiándolos o castigándolos en consecuencia, estamos haciendo algo parecido a utilizar un mapa: un mapa no es la realidad, pero la representa de manera convencional: permite hacerse una idea de ella, incluso sumamente precisa, pero siempre que no confundamos uno y otra. La metáfora teatral se corresponde con la realidad sólo en sentido figurado, y se utiliza con el fin de sugerir una comparación que facilite la comprensión del objeto. Pero ni la realidad social es literalmente un teatro, ni los actores sociales literalmente representan papeles; sí hay, por supuesto, expectativas compartidas de conducta a las que hemos optado por llamar roles en la medida en que su incumbente se comporta como si se tratara de papeles teatrales; pero cuando llamamos a todo eso "teatro", cuando decimos que la interacción producida en la realidad social es como un teatro, no hacemos sino valernos de un tropo, una metáfora, para mejor entender la complejidad de la realidad, pues ¿Cómo es que hay comportamientos esperables? ¿Cómo sabemos lo que hemos de hacer para que nuestros interlocutores estén satisfechos con nosotros? ¿cómo es que podemos predecir la conducta de alguien a partir de lo que es usual en una sociedad, y no en otra? No es el caso de incluir en estas páginas un status quaestionis de la teoría del rol, ni de insistir en la tradición que tiene en la sociología: sus planteamientos, al menos hasta 1960, fueron brillantemente recogidos por Naegele (1961,vol.I: 147), y los clásicos trabajos de Merton, Mead, Linton, e incluso Freud (con su famoso estudio sobre la interiorización del rol de mujer), no necesitan ser recordados. Baste, pues, ahora un sumario resumen de las notas imprescindibles para el concepto. 


\section{ROLES $^{3}$}

Referirse a la realidad social a través de la metáfora teatral recuerda de inmediato el auto sacramental de Calderón, de 1635, que lleva por título El gran teatro del mundo. La obra consiste en que, de acuerdo con la fórmula del teatro dentro del teatro, se va a representar una obra escrita por un personaje denominado "El autor", con actores que representarán papeles de carácter simbólico, como "La hermosura", "El rico", "El labrador", "El pobre", etcétera. "El autor" no ha dado un texto escrito a sus personajes para que lo aprendan y reciten, sino sólo algunas indicaciones para que sepan qué papel representan y cómo deben actuar, improvisando su actuación. Al acabar la representación los personajes son juzgados en el escenario sobre cómo han representado el papel que les fue encomendado en el reparto. Pues bien, en la misma línea se mueve Raymond Aron: "La sociedad -dice- es una suerte de commedia dell'arte en la que los actores tienen el derecho de improvisar siguiendo lineamientos preestablecidos. Es un extraño teatro [...] que no admite ninguna distinción entre el escenario y la platea, y en el que todos pertenecen a la vez al elenco y al público" (1969: 13-14). En resumen: aunque de hecho se improvise en la representación del papel asumido, la improvisación no es enteramente libre, sino que ha de sujetarse a unas pautas preestablecidas con más 0 menos detalle. La metáfora teatral implica que somos personajes que representamos un papel (que no consiste sólo en recitar un texto mejor o peor aprendido), aunque no nos limitamos a ser actores, sino que a la vez somos espectadores: no sólo de cómo alter representa su papel, sino incluso de cómo lo represento yo mismo: me escucho, compongo la figura, recreo mi retórica, etc. Las acciones de cada uno dirigidas a otros (las interacciones) están siempre pautadas, por lo que, al menos hasta cierto punto, son siempre repetitivas y predictibles. También son interactivos los actos individuales y solitarios, pues de alguna manera están los otros presentes en ellos. En todo caso, las acciones las llevan a cabo los individuos, pero no se trata de conductas individuales, sino sociales. Precisamente por ello le interesan a la sociología los individuos y sus conductas, porque en ellas se expresa la sociedad: los individuos son, para la sociología, portadores (Träger) de pautas sociales. Ello no quiere decir, sin embargo, que seamos una especie de marionetas en manos de la sociedad: representamos, es cierto, nuestro papel, pero lo hacemos mejor o peor, más o menos aprendido, y en un juego de expectativas mutuas: los demás esperan algo de mí y yo espero algo de ellos. Pero las expectativas nunca son rígidas, de modo que (casi) siempre es admisible un cierto grado de discrepancia entre la conducta prescrita y la performance o representación efectiva.

Como señala Simmel, "toda relación entre personas hace nacer en cada uno una imagen de la otra [...] la acción recíproca entre los individuos se funda en la imagen que

\footnotetext{
${ }^{3}$ El término rol fue incorporado a la $22^{\mathrm{a}}$ edición del DRAE, del año 2001, con el significado con que aquí se maneja.
} 
cada cual se forma del otro [...] Así, nuestras relaciones van desenvolviéndose sobre la base de un saber mutuo, y este saber se funda a su vez sobre la relación de hecho" ${ }^{4}$. De modo, pues, que los sujetos que interactúan siempre saben algo los unos de los otros: por lo menos lo que se deduce a simple vista de la edad, sexo, status, etc., y de la situación en que se produce el contacto (en el trabajo, en vacaciones, en la calle, etc.), todo lo cual da ya una idea del papel social que esa persona ha de representar, y que hay que esperar que represente. Nótese, pues, que cada uno va a valorar la conducta del otro en el contexto de la situación en que se encuentren, tal y como la hayan definido. Las definiciones de la situación que uno y otro hagan no son aleatorias, erráticas o caprichosas, sino que a su vez están socialmente orientadas: aprendemos a definir situaciones, y nuestras habilidades para ello son adquiridas y dependen de nuestra edad, sexo, procedencia del medio rural o urbano, educación, clase social, etc.

Antes, pues, de actuar, ego define la situación y de acuerdo con ello actúa y reacciona a la actuación de alter: lleva a cabo su performance, representa su rol. El rol es una mezcla de las expectativas que compartimos (en la medida en que las compartimos, que es variable), de la definición que hacemos de la situación (que no siempre hay que suponer precisa, acertada y coincidente), y de la conducta efectiva que llevamos a cabo. $Y$ esa mezcla se sintetiza en la representación de un papel social mejor o peor aprendido. Todo lo que sucede en el escenario tiene lugar en presencia de terceros: las relations tienen lugar in public, como señala el título del libro de Goffman (1979), lo que hace que mi representación vaya dirigida no sólo al alter con quien interactúo, sino a todos los demás (aunque ni siquiera estén efectivamente presentes). Representamos constantemente, pues, papeles sociales de los que somos intérpretes, y en parte también autores, y ello ante un peculiar auditorio compuesto también de actores que "se saben" (al menos en sus líneas generales) el papel que yo represento: tienen expectativas al respecto, y van por tanto a juzgar de la bondad de mi performance, premiándome o castigándome por ello. Y es que el rol no es sólo prescripción, sino representación o interpretación, y salirse demasiado del papel no es apreciado, sino rechazado por razones de seguridad: por la necesidad de saber a qué atenerse con el interlocutor de que se trate. La excentricidad en la representación de un rol no está bien vista, ya que interpretar un papel no es asunto privado, individual, sino público o social; pero la valoración que de mi performance se haga no se limita nunca a lo que se supone que hay que decir ni al estricto esquema de lo que hay que hacer, sino que versa sobre toda la complejidad de mi puesta en escena.

Los roles están "escritos" (definidos, regulados) socialmente, en el sentido de que nadie se los inventa; y obviamente no constituyen una herencia biológica (no son "naturales") sino culturales (se aprenden). Aquí viene muy a cuento la frase de Simone de Beauvoir de que no se nace mujer, se llega a serlo ("on ne naît pas femme: on le devient")

${ }^{4}$ Simmel (1977:359). Véase el capítulo que dedica a los roles y a la socialización en ellos Joas (1998: 242 y ss). 
(1949, vol.l: 285). Algunos roles hay que aprenderlos a fondo, porque son los que a uno le tocan, y de otros basta con aprender cuáles son sus líneas esenciales, para tener expectativas acerca de la conducta de los demás. Los que no somos conductores del autobús de una línea urbana hemos de conocer, al menos desde fuera y superficialmente, ese rol, para saber, como viajeros, qué conducta podemos esperar de ellos. De modo que los papeles sociales son expectativas compartidas de conducta: uno se mueve en terreno conocido cuando sabe más o menos lo que van a hacer los demás, y se trata de una experiencia tranquilizadora tanto porque es compartida, como porque reduce la incertidumbre. Todo el mundo representa los papeles sociales que le han tocado (adscritos, de nacimiento), o que se le han atribuido (adquiridos, sea que hayan sido logrados meritocráticamente 0 , por el contrario, como consecuencia de comportamientos rechazables que llevan a posiciones sociales degradadas o estigmatizadas); son siempre varios, se representan mejor o peor, y se aplaude o abuchea por ello. Pero la representación, como en el teatro de verdad, nunca es mecánica: el papel "se hace" con más o menos fidelidad, incluso con cierta "creatividad" respecto de lo establecido: hasta cabe una cierta separación del "texto" de la obra, a lo que algunos roles se prestan más que otros. Porque, en efecto, hay roles socialmente muy rígidos y formalizados (el de conductor de autobús, por ejemplo), y otros muy flexibles y creativos (el de profesor universitario, por ejemplo). Pero conviene insistir en ello.

Al poner en relación la experiencia cotidiana con el mundo de los valores (desde el que se construye el de las normas), Agnes Heller piensa que "nada más natural que cada categoría de orientación valorativa sea un concepto del lenguaje coloquial", ya que dichas categorías "influyen realmente sobre la totalidad de nuestras actividades sociales: orientan hacia lo que está preceptuado o prohibido, hacia aquello que hay que elegir o es necesario evitar. [...] Las orientaciones de valor vienen 'dadas' en los sistemas sociales", de suerte que si no hay un sistema de normas no hay sociedad; y continúa: "Las distintas categorías de orientación axiológica encauzan el comportamiento, la acción, las sensaciones y el pensamiento humano" (1980: 48 y 49). Diríase que tales afirmaciones responden a una sociología funcionalista, 0 al menos durkheimiana, pero en realidad tienen un sentido muy diferente: vienen formuladas desde la filosofía, y desde posiciones que tienen muy poco de conservadoras. De hecho, la autora sostiene que las categorías de valor, que forman el principio ordenador de nuestro pensamiento y nuestra actuación, "constituyen precisamente en su heterogeneidad nuestra sociedad" (1980: 54). Los valores que forman parte de la cultura no son, pues, uniformes: los miembros de una sociedad no comparten valores idénticos, con lo que la sociedad no está, pues, tan integrada como a veces se piensa; las subculturas albergan valores heterogéneos, muchas veces conflictivos, y nótese que a juicio de Heller ello es constitutivo de la sociedad. Pero eso no es todo: en segundo lugar, ese papel de principio ordenador del comportamiento que se atribuye a los valores no es determinante del mismo; nuestra conducta no es una respuesta automática a las normas fundamentadas en los valores: una cosa son los valores y normas que hemos interiorizado en nuestros procesos de socialización, y otra diferente la conducta que llevemos a cabo, que "tiene 
que resultar adecuada a la situación y al sujeto y no sólo al objeto": tanto más cuanto que "cada hombre es un individuo irrepetible y cada situación constituye un fenómeno individual irrepetible"(1980: 71). Obviamente no es el caso discutir aquí si esta opinión de Agnes Heller implica una cierta minusvaloración de la evidencia empírica relativa a las pautas observables de conducta: bastará con aceptar que la conducta individual no viene determinada, sino influida (como ella misma dice) por los valores y normas del actor, lo que implica una diferencia importante con los planteamientos funcionalistas. Para Parsons, por ejemplo, cuando en el sistema de la acción hay una pluralidad de individuos surge como propiedad emergente un principio de racionalidad coercitiva que descansa sobre una regulación normativa de la conducta, de modo que la sociología desarrolla una teoría de los sistemas de la acción social "en la medida en que estos sistemas pueden ser entendidos en términos de la propiedad de la integración de valores comunes" (1968: 930). En consecuencia, si el sistema social ha de subsistir ha de ser gracias a su coherencia con el de la cultura a través de la socialización y del control social; sin embargo, Parsons admite que esta construcción no es realista, en el sentido de que ninguna sociedad histórica consigue la plena integración y estabilidad: su estado natural es de cierto grado de desajuste, desviación y conflicto. No obstante sostiene que el concepto de estructura se refiere a los "elementos de establecimiento de pautas en el sistema", de modo que "consiste en pautas institucionales de cultura normativa" (1961: 36) y, considerada como relativamente constante, contiene básicamente, pues, los valores y las normas de conducta de ellos derivadas. Lo cual supone para Dennis Wrong una concepción artificial del hombre y de la sociedad, que ve al primero como "sobresocializado" y a la segunda como "superintegrada" (1961: 184); Wrong señala que Freud concibió el superego, en tanto que depósito de las normas sociales internalizadas, en permanente tensión y conflicto con otros impulsos y motivaciones de la conducta, la cual no se desenvuelve, ni mucho menos, de total conformidad con las normas sociales, de manera que con frecuencia la conformidad de la conducta con ellas es consecuencia de la coacción y no de la convicción (1961: 188), lo que pondría en cuestión, al menos en parte, el diseño parsoniano. En todo caso, las tesis de Heller no implican determinismo alguno para la acción social, y constituyen un argumento más para situar los valores y las normas de conducta de ellos derivadas en un plano en el que ha de hablarse de influencia y de condicionamiento, y no de conformidad más o menos automática.

El planteamiento teatral (o "dramatúrgico", como también se le llama) tiene la ventaja de que recoge y expresa muy bien las nociones de aprendizaje y representación, de rigidez y flexibilidad, de aplauso o abucheo: todos los actores conocen las líneas generales de todos los roles (o, al menos, de muchos de ellos). Nuestras conductas no son improvisadas ni aleatorias, sino que están pautadas, pero no determinadas: hay pocos papeles sociales completamente rígidos, y en la inmensa mayoría de ellos caben formas más o menos personales de representarlos. Cada actor representa a su manera el papel, de la manera que le es propia, pero los límites de la variación, o de la espontaneidad, están definidos en el propio papel con mayor o menor flexibilidad o rigidez. La conformidad con el rol, en todo caso, no consiste sólo en ajustar nuestra conducta a una norma general, 
sino en responder a las expectativas que tienen al respecto nuestros interlocutores. Por eso la conducta puede ser conforme con el rol para unos y desviada para otros, según el techo cultural bajo el que se muevan: las expectativas varían, y un grupo puede sancionar severamente una conducta rigurosamente conforme con lo prescrito, cuando lo prescrito es cuestionado o rechazado por los valores de dicho grupo.

El conflicto está, pues, a la base de la interacción social, pues no sólo no estamos sobresocializados en una sociedad superintegrada, sino que la cuestión es más compleja: cultura dominante versus subculturas discrepantes o incluso contrarias. Desde este punto de vista la definición de los roles es conflictiva: los roles de hombre y mujer en una cultura machista pueden representarse de manera conformista, en cuyo caso los actores son premiados por los (y las) machistas y sancionados por los (y las) feministas, y viceversa. Por tanto, lo que procede es ver qué segmento o proporción de la población respalda la cultura dominante, y quiénes, o en qué proporción, la rechazan (e incluso qué gentes hay indiferentes al respecto, lo que con seguridad implicará una tercera posición).

La variedad de roles puede ordenarse, con cierta tosquedad, en dos grupos básicos: unos de nacimiento (o adscritos: sexo, edad, ser hijo o hija, origen rico o pobre, etnia, etc.) y otros logrados (o adquiridos: nivel de estudios, profesión, ser padre o madre, clase, etc.). Mi lugar o posición en la estructura social determinará qué roles he de aprender, qué papeles he de representar: los roles "de nacimiento" tienen una importancia extraordinaria para nuestra participación en el Gran Teatro. Por su parte, los roles adquiridos (sobre todo los que tienen que ver con el mercado de trabajo) son menos susceptibles de que una situación de conflicto cultural genere expectativas de rol contrapuestas 0, al menos, diferentes: por ejemplo, el rol de albañil, o de cartero, o de conductor de autobús, parecen poco propicios a generarlas (aunque sí, por ejemplo, el de profesor de universidad, menos definido). Se representarán mejor o peor, y ello permitirá juzgar a sus incumbentes. En todo caso, hay muchas conductas que tienen que ver con roles adscritos, que exigen la mayor conformidad, so pena de sufrir las sanciones sociales propias del caso.

El escenario de la representación es confuso, ya que no suele haber un director de escena, sino que se supone que los actores se dirigen solos (en un ordine senza piano, como diría Infantino $0^{5}$. 0 mejor, se dirigen mirándose unos a otros, para ver cómo reaccionan los demás ante lo que uno está haciendo. Además, en la escena que se representa no hay monólogos, sino que todos actúan y hablan a la vez. Se trata de una situación relativamente ordenada (el "orden social"), en la medida en que cada uno representa su rol, y desordenada y extremadamente confusa, ya que todos lo hacen al mismo tiempo, de manera aparentemente caótica. Todo este planteamiento encaja,

\footnotetext{
${ }^{5}$ Infantino (1995). Pero por el hecho de consistir en papeles sociales, los roles implican reglas y expectativas más o menos precisas, esto es, tienen un piano. Aunque no sólo los roles están pautados: también lo está la interacción que tiene lugar entre sus incumbentes/interlocutores, incluso de manera ritual.
} 
pues, con la teoría de la acción social, y plantea una vez más la cuestión acción social versus estructura social (en la que aquí no vamos a entrar).

Los actores, en el escenario, no representan "teatro del absurdo": todo lo que ven, lo que hacen los demás, lo que hacen ellos mismos, tiene sentido para ellos, y para los demás. Seguramente no para todos, pues siempre habrá quien perciba en las cosas un sentido diferente, incluso opuesto, al predominante (o quizás habría que decir al dominante, pues en definitiva de eso se trata). En todo caso, cabe imaginar un espectador ajeno al sentido que lo que sucede ante él pudiera tener (un espectador que careciera del "punto de vista del nativo"), para quien la actividad observada sería ininteligible. Pero no tardarìa en percibir bajo la aparente confusión el orden social, al percatarse de que se trata de conductas pautadas y repetitivas, no aleatorias, dependientes de la posición social de cada uno: tendría que aprender a entender lo que la gente hacía, y terminaría admirándose de que lo que parecía caótico fuese en realidad muy ordenado, por más que el orden fuese arbitrario y no llegase en ningún momento a ser completo. La posición social, pues, determina las relaciones sociales (que constituyen la materia de la realidad social), y esas relaciones sociales delimitan la representación de roles en el escenario social. Pero si la condición humana de animal social (de zoon politikon) hace que, ciertamente, no seamos libres ni nos movamos al azar, tampoco estamos determinados por la cultura. Y es en esas condiciones de imprecisión pautada en las que cada uno de nosotros ha de "hacer" no ya un papel, sino varios, que ha tenido que aprender, y que sus interactores, su público, esperan verle representar.

En resumen, la realidad social consiste en relaciones sociales; la estructura de dicha realidad social está formada por el conjunto de relaciones entre posiciones sociales ubicadas en un espacio determinado por las dimensiones cultural, demográfica, política, económica y temporal. Las posiciones sociales son, a modo de alvéolos, lugares sociales conectados entre sí por relaciones definidas y agrupados por afinidades compartidas (por ejemplo, de clase social): como una suerte de gran organigrama. Una retícula, pues, de posiciones, distancias y conflictos sociales en la que se produce la interacción social mediante la representación de los roles.

\section{LOS ROLES Y EL HOMO SOCIOLOGICUS}

El texto Homo sociologicus, fechado por Ralf Dahrendorf en Hamburgo en 1959, lleva como subtítulo el de Un ensayo sobre la historia, significado y crítica de la categoría del rol social, considerado este concepto como "una categoría elemental para el análisis, propiamente sociológico, de los problemas del comportamiento social", "en que aparezcan incluidos el individuo y la sociedad" (1973: 39 y 51): tal planteamiento constituye todo un progama de investigación, pues se nos dice que "en el ámbito en que se entrecruzan el hombre y el hecho de la sociedad, habremos de buscar los elementos de una ciencia, cuyo objeto sea el hombre en la sociedad"; pues bien, "en el cruce del individuo y de la sociedad se halla el homo sociologicus, el hombre como portador de roles sociales pre- 
formados. El individuo es sus roles sociales, pero estos son, a su vez, el hecho molesto de la sociedad" (1973: 52). La primera afirmación parece tener pretensiones ontológicas: se nos dice que el hombre es sus roles. Pues bien, creo que lo que el autor quiere decir es que el hombre es sus roles para los demás, para sus interactuantes. Aunque quizás pueda irse más allá: cabría suponer que a lo que está queriendo aludir el autor es a la condición de zoon politikon del ser humano, que es animal social precisamente por su condición de miembro de una polis, de una sociedad que lo ha producido como tal. Desde este punto de vista la noción de rol adquiere un sentido fuerte, definitorio de la condición humana, que quizás sea precisamente el que Dahrendorf quiera darle con su tesis de que el hombre es sus roles.

Pero, en segundo lugar, ¿por qué habla Dahrendorf en este contexto de "el hecho molesto de la sociedad"? La respuesta es clara: la sociedad nos impone su dominio (1973: 49, n.5), forzándonos a seguir una determinada conducta si uno no quiere afrontar la correspondiente sanción. Podríamos decir, incluso, que a veces no existe siquiera la opción de no cumplir con lo prescrito, como sucede con el habla, sujetos como estamos a la lengua materna y a las variedades locales de la misma. Pues bien, como acabamos de ver, si el individuo es sus roles, "estos son, a su vez, el hecho molesto de la sociedad": en ese entrecruzamiento entre hombre y sociedad se produce el dominio de la segunda sobre el primero, de modo que a través de la imposición de los roles se constituye el homo sociologicus; "si acepta y abraza las exigencias que se le presentan, abandona el individuo su intacta individualidad, pero obtiene el beneplácito de la sociedad en que vive; si el individuo se resiste a tales exigencias, puede conservar una independencia abstracta e inoperante, pero es víctima de la ira y las dolorosas sanciones de la sociedad" (1973: 61). Lo ha sabido ver con claridad Castillo, que señala "el doble carácter, coactivo y externo al hombre, de las normas sociales", con lo que la sociedad resulta "desagradable y molesta": un hecho molesto del que no podemos evadirnos sin sufrir las consecuencias (Castillo, 1983: 147). Bien es verdad que, como recuerda el propio Castillo, en una obra posterior Dahrendorf relaciona los conceptos de ligadura (algo externo que se impone) y de opción (posibilidades de actuación) como complementarios, de modo que "las oportunidades vitales son el producto de opciones y ligaduras" (1979: 31): el homo sociologicus sufre la ligadura de los roles cuyas normas se le imponen, pero precisamente a través de ellos puede optar a sus oportunidades vitales como ser humano.

Pues bien, si el homo sociologicus es una construcción científica, como lo es el homo œconomicus, también lo es el concepto de rol social, como lo es el de átomo, dice el autor. Pero "el átomo o el rol social, aunque inventados, no son pura invención" de la ciencia (Dahrendorf, 1973: 53): el rol es una categoría que se impone a quienes pretenden captar como objeto de conocimiento al ser humano en sociedad. Y su origen, como el del término persona o máscara, está en el teatro, con lo que gracias a dicha metáfora pueden señalarse una serie de notas que le son propias (Dahrendorf, 1973: 55): el rol es algo dado al actor, algo socialmente preformado, que existe fuera de él, y que ha de aprender para poderlo representar; consiste en un conjunto de modos de conducta prescritos para ser desenvueltos por el actor, y que han de articularse con los atribuidos 
a otros actores; ningún actor se limita a asumir solamente un rol, sino que ha de aprender y representar multitud de ellos; y, por último, destaca Dahrendorf que tras los roles subsiste el yo del actor, que puede despojarse de ellos (al menos hasta cierto punto) una vez que abandona el escenario, y ser él mismo: tesis que si puede ser más o menos válida para los roles adquiridos, no lo es tanto para los adscritos. Y señala con agudeza el autor que algunos estudiosos transforman el concepto sociológico de rol como forma de conducta previamente dada que se impone al actor, en un concepto socio-psicológico de regularidades observadas en el comportamiento individual de la vida cotidiana (1973: 58), pasando en el mejor de los casos, cabría añadir, de la perspectiva macro a la microsociológica.

Como bien señala el autor, no sabemos cómo va a comportarse efectivamente el incumbente de un rol, pero sí sabemos lo que se espera de él; y es que los roles son, en efecto, expectativas compartidas de conducta: "Cuando hablamos de roles sociales, siempre nos referimos exclusivamente a comportamientos esperados, es decir, al individuo que se ve enfrentado a demandas existentes fuera de él mismo, o a la sociedad, que enfrenta al individuo con determinadas demandas [...], con formas preestablecidas de comportamiento" (1973: 71). En resumen, pues, los roles son complejos de normas de conducta cuyo contenido ha sido fijado por la sociedad, y suponen una obligación para el individuo, que no puede eximirse de dichas normas sin sufrir daño: "los roles sociales constituyen una coacción, ejercida sobre el individuo", pues "la sociedad dispone de sanciones, con cuya ayuda es capaz de imponer sus prescripciones" (1973: 73). Pues bien, y por referirnos sólo a las sanciones de carácter negativo que castigan la disconformidad, Dahrendorf establece agudamente que dichas sanciones no son sólo sociales, a través del aislamiento, el rechazo, la maledicencia o el ridículo de quien incurre en ellas, sino que pueden llegar a ser formales, jurídicas: y es que hay diferentes niveles en las expectativas de conducta. Las más rígidas son las prescripciones imperativas, establecidas en el Derecho vigente y cuyo incumplimiento está sujeto a persecución judicial: las normas sociales han llegado a convertirse en normas jurídicas, garantizando así la sociedad la observancia de las expectativas de conducta de que se trate. Pero ello, nos dice, "no debe inducirnos [...] a ver en leyes y Tribunales la única forma de expectativas de rol y sanciones", como tampoco en los reglamentos y estatutos establecidos por toda clase de organizaciones (1973: 76 y 77), ya que con un menor grado de rigidez existen expectativas que implican una obligación moral, e incluso meras expectativas de posibilidad, como las llama el autor, que casi no implican prescripción alguna, y que en la práctica sólo comportarían sanciones positivas que premien la conformidad de la conducta.

En mi opinión, estas tesis de Dahrendorf tienen el interés de subrayar el diferente grado de institucionalización de los roles sociales, que llega al máximo cuando la prescripción de conducta está establecida en una Ley y es controlable judicialmente (manifestándose así la fundamentación social del sistema jurídico), y al mínimo cuando la prescripción casi no existe y la sanción es sólo positiva. Pero todo ello tiene el inconveniente de juridificar quizás en demasía las prescripciones imperativas: si, por ejemplo, el 
rol de policía uniformado está minuciosamente regulado por las normas jurídicas, el rol de madre es mucho más borroso desde el punto de vista del Derecho, aunque socialmente las expectativas que le son inherentes estén establecidas con análoga minuciosidad, aunque de manera informal (al menos de forma no escrita). E incluso cabe dudar de que pueda existir en el ámbito de los roles un "comportamiento social no regulado [...] en que el individuo es libre de configurarse por sí mismo sus roles y comportarse así 0 de otra manera" (1973: 77 y 80): ausencia de regulación que sin duda puede existir para muchas formas de conducta, pero al margen, como digo, del campo de los roles. En resumen, la cuestión es la esperable en materia de determinismo social, respecto del que concluye el autor que "el problema de la libertad del hombre como ser social es un problema de equilibrio entre el comportamiento determinado por el rol y la autonomía, y el análisis del homo sociologicus parece confirmar, al menos en este punto, la paradoja dialéctica de libertad y necesidad" (1973: 82): una respuesta insatisfactoria, como cabía esperar.

Tras apuntar el autor su aceptación de la tesis freudiana del Superego como conciencia vuelve a insistir en que "el ámbito del comportamiento regulado por expectativas obligatorias está delimitado y no determinado", de modo que cada rol deja un espacio libre a su incumbente (1973: 106). Y se preguntará explícitamente más adelante: "¿Es el hombre un ser prefigurado en su comportamiento, y por tanto, susceptible de ser calculado y controlado? ¿O es más bien un ser único, capaz de autonomía y libertad?”. La respuesta apunta más bien a la tesis y antítesis de una contradicción, la que existe entre la libertad (relativa, habría que añadir) del hombre de nuestra experiencia, y la determinabilidad (igualmente relativa) del homo sociologicus (1973: 138-139). En todo caso, dice de manera un tanto simplista, "las pautas de comportamiento individualmente variables caracterizan al hombre de nuestra experiencia diaria, pero no al homo sociologicus" (1973: 117). Sin embargo, cabría recordar que no todos los roles implican el mismo grado de detalle en sus prescripciones, ni exigen el mismo grado de fidelidad a las expectativas: los hay más rígidos y más flexibles, más y menos definidos, más y menos exigentes de la conformidad de su incumbente.

\section{EL DRAMA RITUAL}

No estará de más comenzar este apartado con algunas precisiones sobre la noción de ritual como metáfora complementaria a la del teatro para la comprensión de los fenómenos de la vida social. De acuerdo con Enrique Luque (1988: 873 y ss.), tres son las cuestiones que se vienen discutiendo en torno al concepto de ritual: primero, si se trata de una noción vinculada a lo mágico o religioso, o puede utilizarse en contextos seculares; segundo, si ha de considerarse o no como esencial la carencia de relación entre medios y fines, esto es, la ausencia de racionalidad; $y$ tercero, el papel que ha de jugar en el ritual el factor simbólico, es decir, lo que el rito en cuestión pueda expresar en una suerte de paralenguaje, como señala Lévi-Strauss. En todo caso, existe un acuerdo prácticamente generalizado acerca de que las sociedades modernas no son ajenas en 
absoluto a la utilización de pautas rituales en los procesos de interacción e intercambio, aunque cabe concluir con Luque que los términos de "rito y ritual van camino de significar cualquier tipo de conducta estandarizada" (1988: 873), como por otra parte viene siendo usual en sociología para explicar la reiteración de formas de interacción sujetas a pautas socialmente establecidas, y que, de manera similar a lo que sucede con la cultura y las subculturas, son a la vez en cierta medida comunes a toda la sociedad, y en cierta medida específicas de determinados grupos sociales (piénsese, por ejemplo, en las pautas de interacción diferenciales según grupos de edad, o que varían según la clase social, o que implican comportamientos diferentes en escenarios diferentes, etcétera).

Pero veamos alguna evidencia concreta. El ritual del atuendo en determinados escenarios puede llegar a ser muy riguroso, hasta el punto de que todas las conductas sean efectivamente conformes con la norma de que se trate. Valga como ejemplo la utilización obligada de ciertas prendas (como sucedía antaño con el sombrero o la corbata), que se ha trocado en su eliminación actual: no se trata de que haya desaparecido la norma que imponía su uso como prenda ritual para determinadas clases sociales y ocasiones, sino que ha sido sustituida por otra igualmente obligatoria, ahora prohibitiva ${ }^{6}$. Otro ejemplo más complejo podría ser el de los rituales del cortejo, sobre el que los etólogos llamaron pronto la atención, especialmente en ciertas familias de aves, y antropólogos y sociólogos entre los seres humanos: la mayor parte de las culturas han establecido procedimientos de aproximación dirigidos al emparejamiento entre sexos y la reproducción, con objeto sobre todo de dotarlos de una dimensión pública que evitase malentendidos y garantizase en lo posible la moral prevaleciente en la sociedad (o en el grupo social de que se trate): pues bien, tales rituales cambian, a veces de manera muy llamativa, pero conservando siempre su razón de ser. Y es que la vida cotidiana, como "gran teatro del mundo", está llena de rituales de todo tipo (atuendo, saludo, "buenas maneras", habla, etc.) que permiten a todos saber a qué atenerse en la interacción social. No me estoy refiriendo aquí al desempeño de los roles sociales (desde los adscritos de sexo o edad hasta los adquiridos de fontanero o médico, todos ellos pautados por rituales específicos), ni tampoco a las estrategias de presentación del yo, sino a las pautas de conducta más comunes de la vida cotidiana.

Señala Kenneth Burke que su metodología para la crítica literaria utiliza como perspectiva general una teoría del drama, un drama ritual del que parten, como los ejes del radio de una rueda, todos los demás aspectos de la acción humana, y propone dicha perspectiva como "una serie de coordenadas que sirva mejor para la interpretación de todos los fenómenos estudiados por las ciencias sociales": esto es, mejor que "la metáfora mecanicista (estímulo, respuesta y reflejo condicionado)" (2003: 129 y 130). He aquí, pues, un humanista que rechaza para las ciencias sociales el generalizado beha-

\footnotetext{
${ }^{6}$ Los actores no son más libres que antes en ese aspecto de su atuendo: hace cincuenta años, la corbata era preceptiva para ciertos grupos sociales y ocasiones (por ejemplo, para los estudiantes universitarios), y ahora es en cierto modo obligatorio no llevarla: una norma ha sustituido a otra.
} 
viorismo de la época, y que prefiere como alternativa una metáfora diferente a la mecanicista: la metáfora teatral del drama ritual. Identifica el autor lo dramático con lo dialéctico como la perspectiva adecuada para el análisis de la historia, pues ésta consiste en un proceso dramático que implica oposiciones dialécticas. Y vuelve de nuevo al ámbito del tropo con otra metáfora más: la historia como una "conversación sin fin", como una discusión interminable a la que nos incorporamos al nacer y abandonamos al morir; de esa conversación sin fin es de la que surgen los materiales del drama, en el que no todo son palabras: Ios intereses materiales que consideraron Bentham, Marx y Veblen forman parte de los "contextos de situación" entre los que se mueven los actores, que "afectan sobremanera al lenguaje en el que hablamos y, por tanto, también al lenguaje en el que pensamos". Y es "interiorizando lo externo [...] mediante la incorporación de estos lenguajes sociales [como] nos construimos a nosotros mismos, nuestras 'personalidades', esto es, nuestros roles (lo cual nos lleva de nuevo a la cuestión del drama)" (2003: 132-133). Pues bien, Burke resume su posición, y yo la resumo a mi vez, de la siguiente manera: "1. Tenemos el drama y el escenario del drama [...] 2. La descripción del escenario es tarea de las ciencias físicas; la descripción del drama es tarea de las ciencias sociales. 3. Las ciencias físicas son un inventario de acontecimientos; las ciencias sociales son un inventario de actos. [...] La historia, sin embargo, se ocupa de 'acontecimientos', de ahí la tendencia creciente en las ciencias sociales a pasar de ser un inventario de actos a un 'puro' inventario de acontecimientos" (2003: 133-134). Y sostiene el autor que "lo que estoy defendiendo es que si nos acercamos a la poesía a partir de la distinción entre situaciones y estrategias, podemos llegar a conclusiones relevantes tanto sobre el contenido como sobre la forma de los poemas. A partir de un análisis de las tácticas y las organizaciones que intervienen en los actos rituales de participación [...] podemos descubrir con más exactitud 'qué ocurre en la poesía'. Según esto, creo que el punto unificador de esta aproximación debe ser el «enfoque dramático»" (2003: 139-140). Pues bien, creo que todo en esta larga cita sugiere la conveniencia de extender la indagación y el "punto unificador" del enfoque dramático desde la poesía a la acción social, como el propio Burke hace según hemos visto más arriba. De modo que el actor está en una determinada situación, desde la que lleva a cabo ciertas estrategias: tener en cuenta ambas cosas permite sin duda el conocimiento del contenido de la acción y de la forma que reviste; y como la acción social consiste en actos rituales de participación teatral, nuestra indagación nos permite descubrir lo que ocurre. En definitiva, de lo que se trata es de percibir la acción social no como un fenómeno caótico ni rutinario, sino ritual (2003: 143), esto es, teatral en la medida en que la interacción social está pautada, aprendida y representada ${ }^{7}$.

\footnotetext{
${ }^{7}$ Véase al respecto la oportuna cita de Sartre (de El ser y la nada) que recoge Goffman acerca del mozo de café que representa el papel de mozo de café de manera totalmente ceremonial: en Goffman (2006:.86) (en el original inglés se dice que el mozo is playing at being a waiter in a café).
} 
En un denso y provocativo libro posterior al que vengo citando (y que para algunos es un exponente clásico del New Criticism, dada su pretensión de que los estudios literarios orienten la totalidad de las ciencias sociales), Burke vuelve a la metáfora teatral, explicando que "empecé con una teoría de la comedia, aplicada a un tratado sobre las relaciones humanas", con el propósito de "formular las estratagemas básicas que la gente utiliza, en infinitas variaciones, consciente o inconscientemente, para superar en inteligencia o simpatía a los demás" (1969: xvi y xvii). Estamos, pues, ante un intento de penetrar en la interacción social a través del análisis del comportamiento humano, entendido éste como una representación teatral. $Y$ afirma que denomina a este método "dramatism", ya que "invita a considerar el tema de los motivos desde una perspectiva que, desarrollada desde el análisis del drama, trata al lenguaje y al pensamiento ante todo como formas de acción" (1969: xxii).

Al utilizar Burke el término "ritual" para referirse a su noción de la vida social como teatro introduce un factor de ambigüedad en el planteamiento, que puede hacerlo confuso. Para apreciar con fidelidad lo que me parece su verdadero sentido, creo que es imprescindible considerar el carácter repetitivo de las acciones rituales, de las que nos dice el autor que "existe una tendencia en la ciencia a sustituir el ritual por la rutina" (2003: 143), tendencia de la que él no participa : en efecto, los ritos se repiten, pero no rutinariamente, sino por su valor simbólico de reglas de juego de la interacción social $y$, por tanto, del orden social existente en cada sociedad. Si una conducta meramente rutinaria es una conducta repetitiva que por su regularidad genera expectativas compartidas, una conducta ritual es algo más: dota de sentido a los procesos de interacción que, precisamente por ello, no pueden ser calificados de rutinarios aunque sean repetitivos. Las acciones rituales son, pues, acciones que se repiten regularmente y que son fuentes de sentido, reduciendo así la incertidumbre del entorno y permitiendo certezas y predicciones, esto es, orden social. El teatro ritual no es solamente una fuente estructurante de orden social, ni sólo su expresión estructurada, sino su símbolo: el símbolo del modo de orden social existente en la sociedad de que se trate, puesto públicamente en escena. Pero Burke, además de diferenciar como algo evidente el ritual de lo rutinario, dibuja en segundo lugar un ámbito laico, secular, para lo ritual, separándose así de quienes lo vinculan con la religión o la magia, que es el caso de la mayor parte de la tradición sociológica. Pues bien, lo ritual, ciertamente, puede venir prescrito como ritual religioso propiamente dicho, relacionado con un mito de esa índole, o como ritual mágico para controlar un fenómeno externo (empírico, dice Parsons). Pero también puede tener su origen y su fuerza de obligar en el depósito de tradiciones de una comunidad: en este caso, que es el propuesto por Burke, no habremos de referirnos a mitos, religión 0 magia, sino a las reglas de un juego secular. 


\section{EPÍLOGO SOBRE NECESIDAD Y RIESGO DE LAS METÁFORAS}

Refiriéndose Richard Rorty a la fabulación de un héroe mítico que inventó el Espejo de la Naturaleza e hizo con ello posible la filosofía moderna, afirma que su propósito es desmontar esa imagen, y consecuentemente sostener que la Filosofía (el conocimiento) no es "espejo de la naturaleza". Según nos dice,

Son imágenes más que proposiciones, y metáforas más que afirmaciones, lo que determina la mayor parte de nuestras convicciones filosóficas. La imagen que mantiene cautiva a la filosofía tradicional es la de la mente como un gran espejo, que contiene representaciones diversas -algunas exactas, y otras no [...]. Sin la idea de la mente como un espejo, no se habría abierto paso la noción del conocimiento como representación exacta (1983: 20).

La filosofía como espejo de la naturaleza, o la Sociología como espejo de la realidad social, son metáforas peligrosas, pues conducen a la idea de la representación exacta, al reflejo especular, cuando en realidad más que captar la realidad la tanteamos. Pero rechazada la tentación de la exactitud derivada de la metáfora del espejo, el propio Rorty acepta, como acabamos de ver, que las metáforas determinan la mayor parte de nuestras convicciones filosóficas (de nuestros conocimientos). Y es que son útiles, incluso necesarias, pues nos permiten penetrar en una realidad de difícil acceso y referirnos a ella: no se trata sólo de mirar (de nuevo la metáfora, "óptica" ahora en expresión de Rorty), sino de decir. hay que hablar de la realidad con un lenguaje de imágenes y metáforas cuando no se puede decir otra cosa. Tal como creo que hay que entender a este autor, son necesarios o convenientes tales tropos, pero sin perder de vista el peligro que les acompaña de considerar al conocimiento que con ellos se logra como exacto reflejo de la realidad.

En este sentido los roles son metafóricos, pero son todo lo que refleja el espejo sociológico al ponerlo frente a la interacción social: lo que nuestra mente ve en ella por encima del aparente caos es la representación de papeles sociales a través de conductas pautadas, rituales, aprendidas en la socialización y esperadas en la interacción. Lo que vemos nos induce a la metáfora: nuestra actuación frente a los demás, y la de los demás frente a mí, las vemos como teatro. Pero no ya como mero tropo retórico, sino como el conocimiento científico posible. Sin embargo, la ciencia no es, ciertamente, espejo de la naturaleza, sino sólo mapa de algunas de sus características: una descripción parcial pero inteligible, siempre mejorable y eventualmente sustituible si no resiste su falsación, o si alguna otra "mirada" ha logrado captar la realidad de una manera más completa o satisfactoria. Así pues, tomarse al pie de la letra las metáforas del teatro y del rol supone trivializar, en el sentido que da Rorty al término (Rorty, 1983: 92 y ss.), la vida cotidiana de los individuos, ya que, en el sentido literal de la metáfora, al concluir la representación del rol el actor recobraría su vida fuera del escenario, saldría del camerino y del teatro y se sumergería en ella. Pero en la realidad no hay una doble vida, la 
teatral de los roles y la cotidiana sin ellos, sino una sola articulada en la representación de varios roles. No acaba el teatro, sino que se vive (metafóricamente) en el teatro, lo que no tiene nada de trivial. Cada actor tiene varias caras (representa varios roles, se mueve en diferentes argumentos), y no puede abandonar el escenario ni salir del teatro, sino que concluye por el momento la representación de un papel (el de camarero, por ejemplo) y comienza la de otro (el de padre, por ejemplo). No hay, pues, que tomar literalmente la metáfora teatral, sino sólo manejarla como un instrumento para describir y explicar el hecho de que todos compartamos expectativas acerca de la conducta que cada uno va a llevar a la práctica en diferentes momentos y actividades, conductas que los actores no se van a inventar, sino a reproducir mejor o peor a partir de las pautas que han interiorizado.

Por su parte, la metáfora que utiliza la noción de ritual como algo diferente de la mera repetición rutinaria por estar el ritual impregnado de sentido puede caer en el idealismo, ya que el sentido puede terminar desapareciendo de la conciencia del actor, que termina llevando a cabo en términos estrictamente rutinarios su comportamiento pautado y predecible, convirtiendo su acción en algo sin sentido, al menos para él. Si las metáforas del teatro y de los roles trivializan la realidad estudiada, la noción de comportamiento ritual ennoblece de alguna manera la rutina de la conducta prescrita, suponiéndole un sentido del que puede de hecho carecer.

He aquí, pues, que las metáforas pueden ser heurísticamente necesarias, pero son epistemológicamente peligrosas en la medida en que pensemos que nuestra indagación sociológica logra un conocimiento de la realidad que la refleja fielmente, literalmente, olvidando así la ambigüedad, la borrosidad y la contingencia que la caracterizan.

\section{REFERENCIAS BIBLIOGRÁFICAS}

Aron, R. 1969. Progreso y desilusión. Caracas: Monte Avila.

Beauvoir, S. de. 1949. Le deuxième sexe, 2 vols. París: Gallimard.

Burke, K. 1969. A Grammar of Motives. Berkeley: University of California Press.

Burke, K. 2003. La filosofía de la forma literaria y otros estudios sobre la acción simbólica. Madrid: Ed.Antonio Machado.

Castillo Castillo, J. 1983. "El molesto hecho de la sociedad". En J.R.Torregrosa y B.Sarabia, dirs., pp. 147161. Perspectivas y contextos de la psicología social. Barcelona: Ed.Hispano Europea.

Dahrendorf, R. 1973. Homo sociologicus. Madrid: Instituto de Estudios Políticos.

Dahrendorf, R. 1979. Life Chances: Approaches to Social and Political Theory. Londres: Weidenfeld y Nicholson. 
Derrida, J.1967. De la grammatologie. París: Minuit.

Goffman, E. 2006. La presentación de la persona en la vida cotidiana. Buenos Aires: Amorrortu.

Goffman, E. 1979. Relaciones en público. Madrid: Alianza.

Heller, A. 1980. Por una filosofía radical. Barcelona: El Viejo Topo.

Infantino, L. 1995. L'ordine senza piano. Roma: La Nuova Italia Scientifica.

Joas, H .1998. El pragmatismo y la teoría de la sociedad. Madrid: Centro de Investigaciones Sociológicas.

Lakoff, G. y M. Johnson. 1991. Metáforas de la vida cotidiana. Madrid: Cátedra.

Luque, E. 1988. "Rito y ritual". En Román Reyes dir., pp. 873-878. Terminología Científico-social. Aproximación crítica. Barcelona: Anthropos.

Naegele, K. D. 1961. "Interaction: Roles and Collectivities". En Parsons, T., Shils, E., Naegele, K.D., y Pitts, J.R., eds. pp. 147-157. Theories of Society. Foundations of Modern Sociological Theory, 2 vols. Nueva York: The Free Press of Glencoe.

Ortega y J. Gasset. 1957. "Las dos grandes metáforas". El Espectador. IV. (1925). Obras Completas, vol.II, Madrid: Revista de Occidente.

Ortony, A. ed. 1979. Metaphor and Thought. Cambridge: Cambridge University Press.

Parsons, T. 1961. "An Outline of the Social Systems". En Parsons, T., Shils, E., Naegele, K.D., y Pitts, J.R., eds., Theories of Society. Foundations of Modern Sociological Theory, 2 vols. Nueva York: The Free Press of Glencoe.

Parsons, T. 1968. La estructura de la acción social, 2 vols. Madrid: Guadarrama.

Rorty, R. 1983. La filosofía y el espejo de la naturaleza. Madrid: Cátedra.

Simmel, G. 1977. Sociología. Estudios sobre las formas de socialización. 2 vols. Madrid: Ed. Revista de Occidente.

Wrong, D.H. 1961. "The oversocialized conception of man in modern sociology". American Sociological Review 26:183-193.

MIGUEL BELTRÁN VILLALVA (Granada, 1935). Es Catedrático jubilado de Sociología y Profesor Emérito de la Universidad Autónoma de Madrid. Premio extraordinario tanto en la Licenciatura como en el Doctorado. Master of Arts en Sociología por Yale University. Ha sido Associate Fellow de la London School of Economics and Political Science, y ha impartido cursos regulares o dado conferencias en muchas Universidades europeas y latinoamericanas. El último libro que ha publicado es La estructura social (Ariel, 2004).

RECIBIDO: $17 / 06 / 08$

ACEPTADO: $26 / 11 / 08$

Publicado on-line: 19 de septiembre de 2009 